\title{
Outer Rod of the Corti
}

National Cancer Institute

\section{Source}

National Cancer Institute. Outer Rod of the Corti. NCI Thesaurus. Code C33238.

The cells forming the outer spiraled tunnel walls in the organ of Corti within the inner ear. 